\title{
Analysis on Application of Cooperative Teaching Mode in Physical Education in Colleges
}

\author{
Yadong Xue \\ College of Physical Education, Yan'an University, Yanan, Shaanxi, 716000, China
}

Keywords: Cooperative teaching mode, Physical education in colleges, Application.

\begin{abstract}
In traditional physical education, the teaching efficiency is low because students are not very interested in physical education curriculum due to the excessively stereotyped teaching mode and rather single training goal and mode. Cooperative teaching mode refers to optimizing teaching resources by coordinating and integrating all factors in teaching so as to help for the implementation of physical education and enhance teaching efficiency. This paper will elaborate the basic meaning, characteristics and strengths of cooperative teaching mode and analyze its specific application in the hope of providing some references for the vast PE teachers.
\end{abstract}

\section{Introduction}

As required by new curriculum reform, PE teachers also made corresponding reforms in physical education of colleges, broke the traditional teaching mode and integrated teaching resources to construct a more scientific and reasonable teaching mode. The implementation of cooperative teaching brings new hopes for physical education in colleges, vitalizes physical education, stimulates students' learning interests and enhances the teaching quality. Targeted trainings have been provided for students based on their gender, ability and other individual difference so that balances can be achieved between the teacher and students, students and students as well as students, teachers and teaching environment.

\section{Meaning of cooperative teaching mode}

Cooperative teaching mode is chiefly centered on "cooperation". The meaning of cooperative is mainly to integrate and coordinate all factors in practices or activities so that all such factors can be fully and reasonably applied and thus all factors are more harmonious. Coordination among all factors can rationalize the overall structure of a practice or activity and can produce new functions and effects. Cooperative teaching mode of physical education in colleges mainly refers to that both the teacher and students jointly participate in teaching activities and effectively complete the integrations of teaching resources including collaborations between the teacher and students, among students, between teaching contents and teaching environments and between teaching and learning etc. ${ }^{[1]}$. Collaboration of resources in many ways can improve the rationality of teaching as well as teaching efficiency. The connotation of cooperative teaching can be summarized in the following aspects:

\section{Coordination between the teacher and students}

The teacher and students, which are not only the subjects but also major operating personnel in teaching activities, must jointly participate in and invest in physical education in colleges. Cooperative teaching mode requires the teacher and students to carry out teaching activities in the capacity of equality and to complete teaching activities through mutual interactions and participations. 
The teacher needs students to coordinate with the implementation of teaching tasks and teaching process; meanwhile, students need the teacher's explanations and supports when learning physical knowledge. Thus, it can be seen that there is a certain coordinative effect between the teacher and students.

\section{Collaboration between psychological teaching and stamina teaching}

As physical education can not only train students' stamina but also contribute to students' psychological development to some degree, psychological teaching and stamina teaching have been integrated and unified in physical teaching of colleges. In physical education, the teacher can strengthen students' psychological education through sports competitions and project trainings etc. so as to cultivate students' firm, tenacious, indomitable and positive attitude ${ }^{[2]}$. Meanwhile, training of sports events can not only enhance students' stamina but also promote their physical health. Psychological education and stamina education, both of which are different effects achieved in a physical teaching process, have common effects and characteristics and mainly aim at enhancing students' social adaptability. Therefore, the collaboration and unification of psychological health, physical health and social adaptability etc. are advocated in physical education in colleges.

\section{Collaboration among the teacher, students and teaching environment}

Teaching activities cannot be separated from the influence of teaching environment. Especially, there is a closer relation between physical education and external environment. Cooperative teaching mode requires the teacher to fully coordinate and utilize external environments in physical education, properly allocate and combine classroom teaching and outdoor teaching and thus strengthen the effectiveness of teaching. For instance, the teacher can help students to decompose the motions of a sports event through multimedia teaching during theoretical teaching so that students can watch demonstrations of motions more clearly and visually; besides, students can repeatedly watch and learn such motions through multimedia. Simultaneously, the teacher can also record students' motions with photographic equipment during outdoor teaching and then display them at class for the purpose of helping students to recognize their own deficiencies and contributing to the standardization of students' motions ${ }^{[3]}$.The teacher can stimulate students' learning interest and enhance the teaching efficiency through the collaboration and association between classroom teaching and outdoor teaching.

\section{Collaboration between physical education and other disciplines}

Cooperative teaching includes not only the internal collaboration of physical education but also the collaboration between physical education and other disciplines, so the teacher needs to fully excavate the innovative contents and teaching functions contained in physical education when conducting cooperative teaching so that it can be combined with other disciplines. This can not only help students to establish interdisciplinary relationships but also help them to absorb helpful contents and teaching methods from other disciplines to contribute to the completion of innovation and reform in physical education.

\section{Characteristics of cooperative teaching}

\section{To emphasize students' subjective role and the teacher's leading role}

Different from the traditional teaching mode, cooperative teaching mode emphasizes the students' subjective role, fully respects students' dominant position in teaching and follows students' law of development. As the organizer and guide during teaching, the teacher provides students with some guidance and assistances due to the pre-existence of teaching objectives, planning of teaching organization process as well as pre-existence and expandability of teachers' knowledge in cooperative physical teaching. Thus, firstly, the teacher needs reasonably set teaching objectives based on students' characteristics and teaching contents before teaching so as to provide guidance for the 
implementation of teaching and students' learning; secondly, the teacher needs to provide students with a learning framework or training demonstrations to help students finish their learning process based on his own ability and teaching contents; finally, the teacher needs to expand the curriculum; during the expansion, the teacher needs to not only guide students to fully use their creative skills, imagination and thinking ability, but also have abundant knowledge resources. In addition, the teacher and students' joint participation and mutual collaboration are most important in cooperative teaching.

\section{To cultivate students' independence in the learning process}

Generally, college students are highly independent and can finish their learning process well without teachers' constant urges and emphases. They often need more space for self-study, so the teacher needs to provide students with sufficient self-development space in physical teaching in colleges. The teacher merely needs to divide students into groups based on their characteristics, allow students to organize intra-group activities independently, help students to complete the learning process from self-study, self-training, self-evaluation, mutual learning, mutual teaching to mutual evaluation via teachers' proper guidance and students' cooperation, give full play to students' creativity and stimulate students' potential.

\section{To attach importance to humanistic permeation}

Physical education in college consists of competitive sports and non-competitive sports. There are some differences and uniformities in them. In the teaching process, the teacher needs to adequately consider students' abilities as well as physical and psychological characteristics and choose targeted teaching contents. As cooperative teaching is people-oriented, the teacher not only needs to focus on learning of physical knowledge and training of sports ability in the teaching process, but also needs to give consideration to students' emotional and attitude cultivation. Teaching objectives designed should not only meet the social demand but also comply with students' law of development. Besides, the teacher should guide students to understand physical knowledge, training skills and training meanings according to physics, biology and other disciplines and thus facilitate the unification of professional knowledge, skills and humanity.

\section{To stress the cooperation between the teacher and students}

Effective cooperation between the teacher and students is an effective way to enhance teaching efficiency. Cooperative teaching mode requires the teacher and students to strengthen the effects of cooperation and collaboration based on equality. Cooperation between the teacher and students is mainly achieved through communications, so sufficient communications and exchanges are required between the teacher and students in cooperative teaching mode. Both knowledge and emotional exchanges are included in such exchanges. Effective fusion, optimization and integration of teaching contents, individual behaviors and competition can be accomplished through communications and exchanges between the teacher and students so that they all can have fun in learning and can understand the significance of physical education ${ }^{[4]}$.

\section{Significances of cooperative teaching mode}

\section{To innovate the mode of physical education in colleges}

In traditional physical education, the same kind of stereotyped teaching mode (teacher's explanation $\rightarrow$ demonstration $\rightarrow$ divided demonstrations $\rightarrow$ students' simulation $\rightarrow$ exercise $\rightarrow$ conclusion) has been continuously used for decades. There are deficiencies in the cultivation of students' comprehensive abilities and psychological education by using this stereotyped teaching mode, which fails to meet the requirement of modern sports. However, the application of cooperative teaching mode breaks the traditional teaching mode. In cooperative teaching mode, students are the subjects, and the teacher mainly inspires and guide students and involves humanity in a proper way, so it helps 
to cultivate students' creativity, thinking ability and healthy psychology. In addition, cooperative teaching pays attention to students' self-study and students engage in active learning from the past passive learning, so students' learning interest is stimulated accordingly. As a result, the teaching can benefit both teachers and students under the dual functions of the teacher's leading role as well as students' subjective role.

\section{To realize two-way communications between the teacher and students}

Usually, one-way instillation method is adopted in traditional physical education. The teacher's "teaching" is the subject in class while students can only passively accept what the teacher teaches without their subjectivity, so the communications between the teacher and students are unidirectional and mechanical. It can be found through classroom observation that only the teacher passionately give a speech and makes operations in class while students become bystanders in the whole class. However, the application of cooperative teaching mode enhances students' subjective role in class, considers students' development as the teaching objective and achieves effective communications between the teacher and students so students can acquire sports knowledge and skills via joint discussion and cooperation between the teacher and students. Since cooperative teaching lays particular stress on students and awakens the consciousness of independent study, it meets the people-oriented teaching requirement in new curriculum reform.

\section{To achieve effective combination of theories and practices in physical teaching}

It is extremely easy to neglect theoretical teaching in physical education. However, the relevant content in theoretical teaching plays a pretty important role students' learning of sports knowledge and cultivation of sports awareness. After the implementation of cooperative teaching, the teacher effectively combines theoretical teaching with practical teaching in physical education; the students can make practices based on the grasp of theories, consolidate and test theories in the process of practices. Besides, it helps students to complete the learning of sports knowledge and skills through the combination of theories and practices, helps students to understand and command sports knowledge and also can effectively prevent body injuries due to improper physical training and operations. Meanwhile, the combination and unification of theories and practices improves the problems of pure teaching or pure practices in traditional teaching so that students can more reasonably realize the significance of physical teaching in the learning process.

\section{Specific application of cooperative teaching in physical education in colleges}

As for the application of cooperative teaching in physical education in colleges, it is required to take effective measures, change teaching concepts and concretely implement it according to the step-by-step principle.

\section{Teacher's introspection on traditional teaching}

Before cooperative teaching is implemented, the teacher must profoundly rethink of traditional teaching and analyzes the disadvantages of traditional teaching so that the teacher can better carry out teaching by using cooperative teaching mode and avoid repeat the same mistakes in the new teaching mode. Moreover, the teacher must realize that one-way instillation, demonstration, simulation and other single teaching modes in traditional teaching only unilaterally emphasize students' mastery of knowledge and motions, fail to embody the connotation of physical teaching and students' integrated development, and have great negative effects on students' long-term development ${ }^{[5]}$. Therefore, the teacher must abandon unreasonable teaching modes in traditional teaching and ceaselessly explore new teaching modes during teaching so as to satisfy the requirements of modern education.

\section{Understanding the connotation of cooperative teaching}

Understanding cooperative teaching mode is the basis for the teacher to carry out cooperative teaching, so the teacher must analyze and understand the connotation of cooperative teaching, realize 
that cooperative teaching focuses on students' participation, cooperation and collaboration, consider students as teaching subjects during teaching, respect students' independent selection and complete interactive teaching on the basis of equality.

\section{Application of cooperative teaching in class}

When implementing cooperative teaching, the teacher must abide by the principles of cooperative teaching. Firstly, principle of equality: in physical teaching, the teacher needs to forget his identity of a senior and participate in teaching in the capacity of equality; in this way, students can break their estrangement with the teacher in their heart and can open their mind to communicate with the teacher so the teacher can understand students' conditions more easily and thus can carry out targeted teaching. Secondly, principle of cooperation: cooperative teaching lays stress on the function of collaboration, which cannot work without cooperation between the teacher and students, so the teacher needs to fully mobilize students' enthusiasm in teaching process and make students to actively participate in teaching; in this way, students can improve their own sports knowledge and skills while coordinating with the teacher's teaching. Meanwhile, the teacher also needs to teaching students in accordance with their abilities and aptitudes and give full play to students' advantages so that the teacher can accomplish the teaching task while coordinating with students' learning process. For instance, when the teacher teaches "aerobics", students need to independently design movements as required by the teacher and show such movements in class. In this way, students' sports skills and creativity can be enhanced. Students can consult the teacher with any problems in the process of movement design; the teacher also effectively completes his teaching task when guiding and helping students to finish their learning task.

\section{Conclusion}

To sum up, application of cooperative teaching method in physical education in colleges can enhance students' comprehensive abilities and teaching effects, contribute to cooperation between the teacher and students, promote communications between the teacher and students and improve students' participation in class. In the process of practical application, the teacher must realize the connotation of cooperative teaching and profoundly rethink of traditional teaching so as to better serve physical teaching in colleges with cooperative teaching.

\section{References}

[1] Yu Shihai. Application of "cooperative teaching" mode in physical skills course, Journal of Hubei Correspondence University, 2014 (22):125-126.

[2] Gao Jinxia. Application of "cooperative teaching" in physical education, Sports Space, 2013 (23):161-161.

[3] Zhang Jie and Yan Yuzhen. Four-dimensional operation mode of physical education under the concept of cooperative education, Teaching and Management (Theories), 2013 (6):146-148.

[4] Jiang Li. Study on physical education mode under the collaborative innovation mechanism of independent colleges, Contemporary Sports Technology, 2015, 5 (16):129-130.

[5] Zhang Xiaohui. Exploration of cooperative teaching in table tennis optional course of regular colleges, Journal of Nanjing Sports Institute: Natural Science, 2012, 11 (4):105-106. 